\title{
Home-use servo-ventilation therapy in chronic pain patients with central sleep apnea: initial and 3-month follow-up
}

\author{
Colin M. Shapiro ${ }^{1,2} \cdot$ Sharon A. Chung ${ }^{1,2} \cdot$ Paul E. Wylie ${ }^{3} \cdot$ Naheed K. Hossain $^{1}$ • \\ Rolf H. O. Holle ${ }^{4} \cdot$ Russell P. Rosenberg ${ }^{5}$ Mark J. Muehlbach ${ }^{6}$. \\ Robert C. Doekel ${ }^{7}$ - G. Vernon Pegram ${ }^{7}$. Jeffrey G. Jasko ${ }^{8}$
}

Received: 1 August 2014 / Revised: 19 February 2015 / Accepted: 10 March 2015 / Published online: 27 March 2015

(C) The Author(s) 2015. This article is published with open access at Springerlink.com

\begin{abstract}
Purpose Opioid treatment of non-malignant chronic pain can result in hypoxemia, hypercarbia, and central sleep apnea. The aim of this study was to determine the initial efficacy of auto servo-ventilation (ASV) and after 3 months of home use. Methods This prospective multicenter interventional study recruited chronic pain patients prescribed $\geq 100$ morphine equivalents for at least 4 months.

Participants Following full-night polysomnography (PSG) to confirm the presence of sleep-disordered breathing, patients were randomized to three additional full-night-attended PSGs with continuous positive airway pressure (CPAP), ASV, and servo-ventilation with an initial mandatory pressure support of $6 \mathrm{~cm} \mathrm{H}_{2} \mathrm{O}$ (ASV manual PSmin 6). Following the PSGs, patients were sent home with EncoreAnywhere and ASV with or without mandatory pressure support.
\end{abstract}

Sharon A. Chung

sachung@uhnres.utoronto.ca

1 Department of Psychiatry, Toronto Western Hospital, University Health Network, 399 Bathurst Street, 7 Main - 429, Toronto, Ontario M5T 2S8, Canada

2 Youthdale Treatment Centres, Toronto, Canada

3 Arkansas Center of Sleep Medicine, Little Rock, AR, USA

4 Western Montana Clinic, Missoula, MT, USA

5 NeuroTrials Research Inc., Atlanta, GA, USA

6 Clayton Sleep Institute, St. Louis, MO, USA

7 Sleep Disorder Center of Alabama, Birmingham, AL, USA

8 Philips Respironics, Monroeville, PA, USA
Results Based on the initial PSG studies, CPAP improved but did not normalize the apnea-hypopnea index (AHI), central apnea index (CAI), or hypopnea index (HI), as all remained elevated. Clinically significant reductions were noted after just one night of ASV and ASV manual (PSmin 6). After 3 months of ASV home use, the AHI, CAI, and obstructive apnea index (OAI) were significantly reduced when compared to baseline diagnostic levels and even when compared to respiratory disturbance indices with CPAP treatment.

Conclusions Initial and home use of ASV for 3 months resulted in significantly lower AHI, CAI, and OAI. This reduction attests to the efficacy of ASV treatment in chronic pain patients on high doses of opioids.

Keywords Chronic pain · Opioids .

Sleep-disordered breathing $\cdot$ ASV

\section{Introduction}

The Institute of Medicine Report on Pain [1] recognizes chronic pain as a public health challenge affecting over 100 million Americans. A statement from the American Academy of Pain Medicine [2] supports opioid treatment for chronic non-malignant pain where medically indicated, when more conservative treatments are ineffective, and if accompanied by ongoing medical monitoring. In 2009, there were close to 80 million prescriptions for opioid analgesics in the USA, with $45.7 \%$ of all opioid prescriptions going to individuals in the age range of 40 to 59 years old [3]. Of note, this age grouping is also associated with an increased risk of developing obstructive sleep apnea (OSA) [4].

Sleep-disordered breathing (SDB) is an all-inclusive term that includes OSA, central sleep apnea (CSA), and mixed apnea (both OSA and CSA). OSA is a condition where there 
is intermittent partial or complete obstruction of the upper airway during sleep that limits or prevents airflow despite continued efforts to breathe. CSA is a condition where breathing is interrupted by the lack of respiratory effort. SDB is characterized by apneas and hypopneas that result in gas exchange abnormalities (hypoxemia, hypercapnia, and hypocapnia), arousal from sleep, and excessive daytime sleepiness. Individuals with undiagnosed and untreated SDB are at greater risk of increased morbidity [5] and mortality [6]. It is estimated that a significant proportion of individuals with OSA, especially those in primary care, remain undiagnosed [7].

Opioids are prescribed to treat chronic pain in up to $90 \%$ of pain management clinic patients [8]. Although opioids are effective in the long-term management of chronic nonmalignant pain [9], opioid use in patients with chronic pain was found to be a significant, dose-dependent predictor for the emergence of CSA and ataxic breathing [10, 11]. In addition to reduced ventilatory responsiveness to hypercarbia and hypoxemia [12], opioids may reduce upper airway tone predisposing the airway to instability and collapse [13]. The decline in EMG activity in the pharyngeal dilator muscles at sleep onset is much greater in patients with OSA as compared to healthy controls [14], suggesting that long-term opioid use could pose a particularly significant risk to patients with undiagnosed OSA. Jungquist and colleagues [11] did not find an exacerbation of OSA symptoms with opioid treatment, but the findings from this lone study require replication.

It is estimated that between 30 and $90 \%$ of patients using opioids have sleep-disordered breathing [10]. In a case study of three patients on sustained-release opioids for chronic pain, Farney and colleagues [15] reported distinct patterns of SDB including ataxic breathing, CSA, sustained hypoxemia, and prolonged obstructive hypopneas. In contrast to what is typically observed in patients with OSA, apnea duration and hypoxemia were more severe and respiratory disturbances were longer in duration in NREM sleep compared to rapid eye movement (REM) sleep.

Continuous positive airway pressure (CPAP) therapy remains to be the standard first-line and effective treatment for OSA. CPAP, when titrated to the appropriate pressure, provides a positive pressure splint to prevent airway collapse and hence prevent the obstruction of the upper airway during sleep. Even though CPAP is highly effective in treating OSA, it has been considered an insufficient therapy for CSA, central apneas and hypopneas, and even periodic breathing that arises with CPAP treatment [16]. Although there is documentation of resolution of CPAP-emergent central apneic activity in some patients, this is not the case for all [17]. Further, Cassel and colleagues [18] noted the appearance of central apneas in patients with OSA on CPAP treatment despite no such activity being present during initial titration with a CPAP device.
A number of studies have demonstrated that CPAP therapy effectively abolishes obstructive apneic events but is not as effective in treating central apneas in patients with heart failure or those on opioid medications $[19,20]$. In fact, in patients taking opioids, both central and obstructive events may be present throughout the night, and in some cases, the application of CPAP treatment results in an increase in the number of central respiratory events [21].

Adaptive servo-ventilation (ASV) therapy has been shown to normalize respiration in patients with Hunter-CheyneStokes respiration in conjunction with heart failure [22] and in patients with persistent CSA despite CPAP treatment [19]. CSA is a common occurrence in patients with heart failure [23], and ASV therapy has been shown to improve prognosis in this patient population [24]. ASV has also been shown to be an effective counter to treat complex sleep apnea syndrome, a situation where central events emerge during CPAP titration for treatment of OSA [25].

Conflicting results have been published about the efficacy of ASV in treating SDB associated with opioid use. In a 2008 study, ASV was unsuccessful in treating SDB in patients on chronic opioid therapy [21]. The study results demonstrated that with ASV therapy, obstructive apneas decreased, while hypopneas increased and central apneas were reduced compared to baseline, but not significantly so. The latter may have occurred as a consequence of applying inadequate settings on the ASV machines utilized in the study, as the authors reported using the default settings for the end-expiratory pressure, minimum inspiratory pressure support, maximum inspiratory pressure support, and backup respiratory rate [21]. Further, ASV algorithms were initially designed to manage CheyneStokes respiration (CSR) where there is a cyclical increasing and decreasing airflow pattern. Opioids may induce a less cyclical pattern, and the ASV algorithm used in the study by Farney [21] may not have adequately responded to a more variable breathing pattern. In contrast, the study by Javaheri [20] demonstrated that ASV was effective in the treatment of SDB in five patients on chronic opioids by significantly reducing both obstructive and central apneas as compared to CPAP. Similarly, Ramar and colleagues [26] found ASV to be equally effective in treating CSA and complex sleep apnea in 108 patients with chronic heart failure as well as those on chronic opioid therapy.

The above findings are a promising indicator for the effectiveness of ASV in patients with SDB associated with chronic opioid therapy but are not without significant limitations. Information is available for the comparative effectiveness of ASV and CPAP only for the initial night of treatment. It remains unknown whether the improved efficacy of ASV over CPAP treatment is sustained throughout months of therapy. Further, only the study by Javaheri [20] investigated patients with chronic pain disorders taking $>100 \mathrm{mEq}$ of opioid medication, but the extremely small patient sample size in that 
study limits the generalizability of the findings. More importantly, the participants in all of the above studies were recruited only from those referred for diagnostic evaluation of sleep apnea. These patients are quite probably those with more severe SDB and are likely not representative of most patients taking chronic opioid medications. Therefore, the efficacy of ASV versus CPAP therapy needs to be investigated over months of treatment in a study with a sufficient sample size and comprised of patients that are representative of the population of chronic pain patients being treated with opioids.

The primary aim of this study was to determine the ability of ASV therapy to correct sleep-disordered breathing with a significant central apnea component in participants with chronic pain who are treated with opioids and are naïve to positive pressure therapy. The study was designed to determine if ASV treatment improved arterial oxygen saturation during sleep and to elucidate if there is a relation between prescribed opioid dose and SDB measures.

\section{Methods}

The System One BiPAP ${ }^{\circledR}$ autoSV Advanced (ASV, Philips Respironics) provides non-invasive ventilation in adult patients with SDB including CSR, CSA, and OSA. The ASV modulates inspiratory positive airway pressure (IPAP) according to the patient's breathing pattern using an internal algorithm. The IPAP levels are automatically adjusted on a breathby-breath basis in order to help stabilize the amount of air being inhaled. The ASV also provides an auto-adjusting expiratory positive airway pressure (EPAP) feature. The autoadjusting EPAP is controlled using the device to treat airway instability or obstruction. The auto-adjusting EPAP feature includes identification of open (presumed to be central apneas) and closed (presumed to be obstructive) airway events as a critical element of its therapeutic benefits. An automatic backup rate tracks spontaneous breathing and provides an effective backup rate of 2 to 3 breaths per min below the spontaneous rate. The auto backup rate is designed to assure a rate closer to the patient's normal rate and avoid overventilating the patient.

The aim of this study was to investigate the efficacy of the ASV with mandatory pressure support (ASV manual PSmin 6) and without mandatory pressure support (ASV) as compared to CPAP, during in-laboratory studies. This study introduced two control measures to promote efficacious treatment in anticipation of the decrease in respiratory drive produced by opioids. For the first control measure, the ASV device was modified to deliver a minimum minute ventilation of approximately 51 . The ASV manual with mandatory pressure support (the second control measure) started at a minimum pressure support of $6 \mathrm{~cm} \mathrm{H}_{2} \mathrm{O}$ (ASV manual PSmin 6) and was adjusted upwards as needed. The ASV (without mandatory pressure support) was set at factory settings. The eligibility criteria for the study are listed in Table 1. After the diagnostic polysomnography (PSG), those with an apnea-hypopnea index (AHI) of $\geq 20$ and central apnea index (CAI) $\geq 10$ events per h of sleep or at least $25 \%$ of total sleep time (TST) below $90 \% \mathrm{SaO}_{2}$ and $\mathrm{AHI} \geq 10$ were asked to continue to participate in the study.

Research ethics approval was obtained for this multisite study. The full study consisted of three phases: screening, inlaboratory treatment PSGs, and 3-month device take-home evaluation. After signing informed consent, demographic data were collected and recorded. A medical history including pain diagnoses and a detailed medication assessment, including the names, frequencies, and dosages of all current medications, were performed. This multisite study involved six sleep clinics (five in the USA and one in Canada).

Participants were instructed to medicate themselves as prescribed prior to and during the screening PSG and all subsequent PSGs. Overnight diagnostic PSGs were performed using standard parameters and were scored based on standard criteria [27] at one central location. Participants who met eligibility criteria demonstrating an AHI of at least 20 and a CAI of $\geq 10$, an OR of at least $25 \%$ of TST below $90 \% \mathrm{SaO}_{2}$, and an $\mathrm{AHI} \geq 10$ were enrolled in the therapy phase of the study and randomized to each of the following full-night in-lab PSG titrations: CPAP, ASV, and ASV manual (PSmin 6). All therapy PSGs were scheduled within 1 week of each other, but not on consecutive nights. The CPAP starting pressure was $4 \mathrm{~cm} \mathrm{H} \mathrm{H}_{2} \mathrm{O}$ and was increased $1 \mathrm{~cm} \mathrm{H}_{2} \mathrm{O}$ for obstructive events associated with snoring, apneas, and hypopneas to a maximum CPAP pressure of $15 \mathrm{~cm} \mathrm{H}_{2} \mathrm{O}$ (or as determined by the physician). The settings of the ASV and ASV manual (PSmin 6) are shown in Table 2.

Based on the investigator's interpretation and review of the three centrally scored therapy PSGs at each study site, each participant was asked to take home either an ASV device or a CPAP device to use for 3 months. The device settings were determined by the investigator based on the centrally scored results. Participants were asked to return to the sleep center for follow-up visits after 1 and 3 months. All take-home devices were equipped with a modem and an SD card. The daily device data were uploaded into EncoreAnywhere ${ }^{\mathrm{TM}}$ (Philips Respironics) during the 3-month at-home portion of the study, in order to assess adherence, therapy pressures, and deviceoutput respiratory indices.

Polysomnographic endpoints were compared between the three treatment arms: CPAP, ASV, and ASV manual (PSmin $6)$. Due to the asymmetric distributions of the endpoints, the nonparametric Friedman analysis of variance was used to compare the related values obtained from the three therapy PSGs. Post hoc pairwise comparisons were performed using the Wilcoxon signed-rank test, with Bonferroni correction. The daily data collected from EncoreAnywhere were 
Table 1 Participants' selection criteria

\begin{tabular}{|c|c|}
\hline Inclusion criteria & Exclusion criteria \\
\hline $\begin{array}{l}\text { Males and females, ages } 21-70 \\
\text { Able and willing to provide written informed consent } \\
\text { Diagnosis of chronic non-malignant pain (pain present } \\
\quad \text { for } \geq 6 \text { months) }\end{array}$ & $\begin{array}{l}\text { Participation in other interventional, sleep, or } \\
\text { pharmaceutical-related research studies within } 30 \\
\text { days prior to giving consent } \\
\text { Workers with variable shift schedules }\end{array}$ \\
\hline $\begin{array}{l}\text { Stable regimen of opioids (oral, transdermal, and/or } \\
\text { intravenous) for chronic pain for at least } 4 \text { weeks } \\
\text { prior to study participation with a prescribed opioid } \\
\text { dose equal to at least } 100 \mathrm{mEq} \text { of morphine per } 24 \mathrm{~h}\end{array}$ & $\begin{array}{l}\text { Previous treatment with positive airway pressure } \\
\text { therapy within } 90 \text { days of providing consent } \\
\text { Participants with any conditions in which positive } \\
\text { airway pressure is medically contraindicated }\end{array}$ \\
\hline $\begin{array}{l}\text { Agreement to undergo an in-lab Diagnostic } \\
\text { polysomnography (PSG) demonstrating an } \mathrm{AHI} \text { of } \\
\text { at least } 20 \text { and } \mathrm{CAI} \geq 10 \text { events per } \mathrm{h} \text { of sleep, OR at } \\
\text { least } 25 \% \text { of TST below } 90 \% \mathrm{SAO}_{2} \text { saturation } \\
\text { and } \mathrm{AHI}>10\end{array}$ & $\begin{array}{l}\text { BMI }>40 \\
\text { Unwilling to wear PAP } \\
\text { Any surgery involving the upper airway, eye, nose, } \\
\text { sinuses, or middle ear within the last } 90 \text { days }\end{array}$ \\
\hline $\begin{array}{l}\text { Agreement to undergo } 3 \text { full-night, in-lab PSGs on } \\
\text { positive airway pressure therapy } \\
\text { Agreement to undergo breathalyzer testing prior to }\end{array}$ & $\begin{array}{l}\text { Major or poorly managed medical or psychiatric } \\
\text { condition that would interfere with the demands } \\
\text { of the study, the use of positive airway pressure, } \\
\text { or the ability to complete the study }\end{array}$ \\
\hline $\begin{array}{l}\text { each PSG visit } \\
\text { Ability to provide reliable documentation of opioid }\end{array}$ & $\begin{array}{l}\text { Previous diagnosis of severe COPD with an FEV1 } \\
\quad<11 \text { or less than } 50 \% \text { predicted }\end{array}$ \\
\hline $\begin{array}{l}\text { medications (e.g., pharmacy records) as treatment } \\
\text { for chronic pain for the previous } 30 \text { days }\end{array}$ & \multirow{3}{*}{$\begin{array}{l}\text { Presence of elevated arterial carbon dioxide levels } \\
\text { while awake }\left(\mathrm{PaCO}_{2} \geq 50 \mathrm{mmHg}\right) \text { due to intrinsic } \\
\text { lung disease or neuromuscular or musculoskeletal } \\
\text { disorders } \\
\text { Participants currently prescribed with 24-h oxygen } \\
\text { therapy }\end{array}$} \\
\hline Willingness to undergo urine drug screening & \\
\hline & \\
\hline
\end{tabular}

averaged within each participant. To calculate an unbiased participants' average of therapy pressure and respiratory indices, the daily values were weighted relative to each day's device usage. The 3-month follow-up data from the ASV and ASV manual (PSmin 6) groups were merged as the respiratory variables from patients using these devices were not significantly different (see Table 5). The 3-month averages of AHI, CAI, obstructive apnea index (OAI), and hypopnea

Table 2 AutoSV device settings

\begin{tabular}{lll}
\hline Settings & $\begin{array}{l}\text { BiPAP autoSV without } \\
\text { mandatory pressure } \\
\text { support (ASV) }\end{array}$ & $\begin{array}{l}\text { BiPAP autoSV with } \\
\text { mandatory pressure } \\
\text { support (ASV PSmin 6) }\end{array}$ \\
\hline $\begin{array}{l}\text { Maximum pressure } \\
\left(\mathrm{cm} \mathrm{H}_{2} \mathrm{O}\right)\end{array}$ & 25 & 25 \\
$\begin{array}{c}\text { Minimum EPAP } \\
\left(\mathrm{cm} \mathrm{H}_{2} \mathrm{O}\right)\end{array}$ & 4 & 4 \\
$\begin{array}{c}\text { Maximum EPAP } \\
\left(\mathrm{cm} \mathrm{H}_{2} \mathrm{O}\right)\end{array}$ & 15 & 15 \\
$\begin{array}{c}\text { Minimum pressure } \\
\left.\text { support (cm } \mathrm{H}_{2} \mathrm{O}\right)\end{array}$ & 0 & 6 \\
Maximum pressure & 21 & 21 \\
support $\left(\mathrm{cm} \mathrm{H}_{2} \mathrm{O}\right)$ & Auto & Auto \\
$\begin{array}{l}\text { Rate setting } \\
\text { Rise time }\end{array}$ & 2 & 2 \\
Humidification & 2 & 2 \\
BiFlex & Off & Off \\
\hline
\end{tabular}

index (HI) for study participants using ASV were compared to the respective measures from the CPAP titration using the Wilcoxon signed-rank test. $p$ values $<0.05$ were considered significant. Where applicable, data in the study are expressed as median (mean \pm standard deviation).

\section{Results}

The details of the patient flow throughout the study are found in Table 3. Randomized study participants, 19 females (56\%) and 15 males, were $50.7 \pm 11.6$ years old and had a BMI of $30.1 \pm 5.4 \mathrm{~kg} / \mathrm{m}^{2}$, and racial composition was $91 \%$ (31) Caucasian and $9 \%$ (3) African-American. On average, study participants were on $390.1 \pm 338.1 \mathrm{mEq}$ of morphine (range 100 $1700 \mathrm{mEq})$. Forty-seven percent (35/74; Table 3) of the participants screened had SDB. Patient demographic data for the total study group and for those participants who completed and those who discontinued the study are shown in Table 4. Compared to treatment with CPAP (Table 5), pairwise comparisons revealed clinically significant reductions in apneahypopnea index (AHI), central apnea index (CAI), and OAI after just one night of ASV and ASV manual (PSmin 6) use. Improvement in respiratory variables did not differ between treatment with ASV without mandatory pressure support or ASV manual (PSmin 6) with mandatory pressure support. 
Table 3 Participants' flow throughout the study

\begin{tabular}{llll}
\hline & Males & Females & Total \\
\hline $\begin{array}{l}\text { Completed study part I: diagnostic PSG } \\
\quad \text { screening }\end{array}$ & 31 & 43 & 74 \\
$\quad \begin{array}{l}\text { Met the criterion AHI of at least 20 } \\
\quad \text { and a CAI of } \geq 10\end{array}$ & 10 & 12 & 22 \\
$\quad \begin{array}{l}\text { Met the criterion of at least 25 \% of } \\
\quad \text { TST below 90 \% SaO } 2 \text { and AHI } \geq 10\end{array}$ & 3 & 5 & 8 \\
$\quad \begin{array}{l}\text { Met both criteria } \\
\text { Failed both criteria }\end{array}$ & 2 & 3 & 5 \\
$\begin{array}{l}\text { Randomized for the study (fulfilled } \\
\text { inclusion/exclusion criteria) }\end{array}$ & 16 & 23 & 39 \\
$\begin{array}{l}\text { Completed study part 2: titration with } \\
\quad \begin{array}{l}\text { CPAP, ASV manual (PSmin 6), } \\
\text { and ASV auto }\end{array}\end{array}$ & 13 & 18 & 34 \\
$\begin{array}{l}\text { Completed study part 3: 3-month at-home } \\
\text { treatment with ASV (auto or manual) }\end{array}$ & 8 & 11 & 19 \\
\hline
\end{tabular}

${ }^{a}$ From the 25 who started the at-home treatment phase of the study with ASV auto or ASV manual (PSmin 6), there were 19 completers

Table 6 presents the PSG sleep architect variables during the four PSG studies: one diagnostic study and three titration studies that were performed in counterbalanced order. Arousal index was found to be significantly $(p=0.021)$ greater during ASV manual (PSmin 6) titration compared to the CPAP titration night. No significant differences were noted for CPAP versus ASV $(p=0.288)$ or ASV versus ASV manual (PSmin 6) $(p>0.99)$. No further differences in the other PSG variables were seen across the three treatment PSGs.

Following the PSG phase of the study, 30 participants started the at-home phase. Per the decision of the individual

Table 4 Patient demographics

\begin{tabular}{llll}
\hline & $\begin{array}{l}\text { Total group } \\
(n=34)\end{array}$ & $\begin{array}{l}\text { Study } \\
\text { completers } \\
(n=23)\end{array}$ & $\begin{array}{l}\text { Study } \\
\text { discontinuers } \\
(n=11)\end{array}$ \\
\hline $\begin{array}{l}\text { Age (years) } \\
\begin{array}{l}\text { Gender distribution } \\
\text { Females }\end{array}\end{array}$ & $50.7 \pm 11.6$ & $52.5 \pm 7.9$ & $46.9 \pm 16.8$ \\
$\quad$ Males & 11 & 14 & 9 \\
$\begin{array}{l}\left.\text { BMI (kg/m }{ }^{2}\right) \\
\text { Race distribution }\end{array}$ & $30.1 \pm 5.4$ & $30.7 \pm 5.0$ & $28.9 \pm 6.4$ \\
$\quad$ Caucasian & 31 & 20 & 11 \\
$\quad$ African-American & 3 & 3 & 0 \\
Morphine equivalents & $390.1 \pm 338.1$ & $399.5 \pm 264.4$ & $370.3 \pm 472.0$ \\
$\quad(m E q)$ & 100 & 100 & 100 \\
Min & 1700 & 812.5 & 1700 \\
$\quad$ Max & & 5 & 6 \\
\hline
\end{tabular}

Major diagnoses included arthritis, back/spine/neck injury, chronic pain secondary to a medical or neurological condition, and headaches/migraines. There were no differences in the demographics between those participants who completed and those who discontinued the study (age: $p=0.32$; BMI: $p=0.43$; $\mathrm{mEq}: p=0.85$ ) site investigators, four study participants $(13.3 \%)$ went home with ASV manual (PSmin 6), and the majority (21 participants, $70 \%$ ) used ASV for 3 months at home. Data for home use of ASV and ASV manual (PSmin 6) were combined. Five participants $(16.7 \%)$ were sent home with CPAP machines. Data from these latter participants will be presented elsewhere. Among the 25 participants who started the at-home phase using ASV therapy, one study participant did not use the device and was subsequently lost to follow-up. After 3 months of ASV home use (Table 7), the AHI, CAI, and OAI were all significantly $(p<0.001)$ reduced when compared to respiratory disturbance indices during the in-laboratory CPAP titration.

Adherence statistics were calculated based on participants' entire 3-month at-home period or their projected 3-month visit date (if they discontinued). The one study participant who did not use their device was included in the intention-to-treat analysis. Adherence to both ASV and CPAP treatment is shown in Table 7. Overall, the ASV devices were used for $49.8 \pm 36.1 \%$ of the days of home treatment with participants using their machines for four or more hours on $30.9 \pm 32.8 \%$ of the days $(N=25)$.

\section{Discussion}

This study is the first to report on both the acute and 3month impact of ASV treatment of SDB in participants with chronic pain taking 100 or more milliequivalents of opioid medication. The design of this study has overcome some of the limitations of previous studies [21, 26]. Specifically, the participants in the current study had not been previously referred for investigation of a sleep breathing disorder and were recruited from chronic pain clinics, not from sleep clinics.

A large epidemiological study estimates that the point prevalence of at least one chronic painful disorder is about 1 in five individuals [28]. Given that the majority of individuals with sleep apnea remain undiagnosed [29], the findings of this study have implications for the routine clinical screening for SDB in participants with chronic pain being treated with highdose opioids. Given that almost half of the study participants were found to have SDB, routine screening for SDB among chronic pain patients is likely to become even more of an issue based on the 2013 statement from the American Academy of Pain Medicine supporting the use of opioids to treat chronic pain combined with reports of increased mortality rates in those taking opioid medications [30].

A previous unpublished investigation found that about one third of participants in a chronic pain clinic spent about one third of the night below $90 \% \mathrm{SaO}_{2}$. ASV manual with mandatory pressure support (PSmin 6) was applied to address issues with decreased respiratory drive in this patient population. For this study, ASV manual (PSmin 6) (with mandatory 
Table 5 Comparison of respiratory variables across diagnostic PSG and titration studies (CPAP, ASV, and ASV manual (PSmin 6))

\begin{tabular}{|c|c|c|c|c|c|c|c|c|}
\hline & \multirow{2}{*}{$\begin{array}{l}\text { Diagnostic } \\
\text { PSG }(N=31)\end{array}$} & \multirow{2}{*}{$\begin{array}{l}\text { CPAP } \\
(N=31)\end{array}$} & \multirow{2}{*}{$\begin{array}{l}\text { ASV } \\
(N=31)\end{array}$} & \multirow{2}{*}{$\begin{array}{l}\text { ASV manual } \\
(\mathrm{PSmin} 6) \\
(N=31)\end{array}$} & \multicolumn{4}{|c|}{$p$ values for pairwise comparisons } \\
\hline & & & & & $\begin{array}{l}\text { Overall } p \text { value } \\
\text { (Friedman test) }\end{array}$ & $\begin{array}{l}\text { CPAP vs. } \\
\text { ASV }\end{array}$ & $\begin{array}{l}\text { CPAP vs. } \\
\text { ASV manual } \\
\text { (PSmin 6) }\end{array}$ & $\begin{array}{l}\text { ASV vs. ASV } \\
\text { manual } \\
(\text { PSmin 6) }\end{array}$ \\
\hline AHI & $32.5(38.8 \pm 31.1)$ & $10.1(17.4 \pm 20.1)$ & $1.4(4.5 \pm 7.3)$ & $2.1(7.6 \pm 16.7)$ & $<0.001$ & $<0.001$ & 0.009 & $>0.99$ \\
\hline CAI & $6.4(16.1 \pm 18.8)$ & $2.4(8.4 \pm 12.4)$ & $0.0(0.2 \pm 0.8)$ & $0.0(0.2 \pm 0.9)$ & $<0.001$ & $<0.001$ & $<0.001$ & $>0.99$ \\
\hline OAI & $1.9(9.7 \pm 15.2)$ & $2.8(4.5 \pm 6.3)$ & $0.0(0.3 \pm 0.5)$ & $0.0(0.5 \pm 1.1)$ & $<0.001$ & $<0.001$ & $<0.001$ & $>0.99$ \\
\hline HI & $10.2(14.8 \pm 12.6)$ & $2.8(4.5 \pm 5.1)$ & $1.4(4.6 \pm 7.4)$ & $3.2(7.9 \pm 16.2)$ & 0.441 & - & - & - \\
\hline $\mathrm{ODI}^{\mathrm{a}}$ & $24.2(32.8 \pm 29.2)$ & $6.0(15.1 \pm 20.2)$ & $1.9(5.9 \pm 8.6)$ & $2.6(9.5 \pm 19.2)$ & 0.161 & - & - & - \\
\hline $\begin{array}{l}\text { Av. } \mathrm{O}_{2} \\
\quad \text { saturation }\end{array}$ & $93.4(92.9 \pm 3.4)$ & $94.9(94.6 \pm 2.3)$ & $94.6(94.6 \pm 2.6)$ & $94.6(94.5 \pm 3.2)$ & 0.627 & - & - & - \\
\hline $\begin{array}{l}\text { Min. } \mathrm{O}_{2} \\
\quad \text { saturation }\end{array}$ & $80.5(79.9 \pm 7.8)$ & $85.0(85.5 \pm 6.0)$ & $85.0(82.9 \pm 16.2)$ & $86.6(79.7 \pm 22.8)$ & 0.991 & - & - & - \\
\hline
\end{tabular}

Data are expressed as median (mean \pm standard deviation). The above $p$ values for the pairwise comparisons, using the Wilcoxon signed-rank test, have undergone Bonferroni adjustment

$H I$ hypopnea index, $O D I$ oxygen saturation index

${ }^{a}$ Defined as the number of times per hour that the oxygen saturation dropped below $4 \%$ of baseline

pressure support) had no benefit over ASV without mandatory pressure support in treating sleep-disordered breathing. ASV use during the initial titration and during the 3 months of home use resulted in significantly lowered AHI, CAI, and OAI. The low treatment adherence rate during the ASV home-use phase of this study is of concern and a limitation of this study but is in line with the low CPAP adherence rates reported in the literature $[31,32]$. As study participants had not previously recognized that they had a SDB, they may not have come to terms with having a sleep disorder and may not have seen the need for the treatment of their SDB. Participants' attitude and beliefs have been shown to greatly impact treatment adherence [33], and patient education is crucial for promoting adherence to treatment for SDB [34, 35]. As such, the implementation of ASV treatment adherence strategies, including educational sessions and distribution of educational materials, should be considered for this patient population. Anecdotally, we have noted clinically that a tailor-made short educational

Table 6 Comparison of PSG sleep architectural variables across diagnostic PSG and titration study (CPAP, ASV, and ASV manual (PSmin 6)) nights

\begin{tabular}{|c|c|c|c|c|c|}
\hline & $\begin{array}{l}\text { Diagnostic PSG } \\
(N=31)\end{array}$ & $\mathrm{CPAP}(N=31)$ & $\operatorname{ASV}(N=31)$ & $\begin{array}{l}\text { ASV manual (PSmin 6) } \\
(N=31)\end{array}$ & $\begin{array}{l}\text { Overall } p \text { value } \\
\text { (Friedman test) }\end{array}$ \\
\hline Arousal index & $20.3(22.9 \pm 13.8)$ & $11.8(14.9 \pm 8.0)$ & $16.6(17.7 \pm 9.4)$ & $\begin{array}{l}16.1 \\
\quad(19.2 \pm 11.7)\end{array}$ & $0.028^{\mathrm{a}}$ \\
\hline Total sleep time (TST) (min) & $407.0(409 \pm 57.8)$ & $387.0(386.8 \pm 60.2)$ & $376.5(377.6 \pm 85.0)$ & $385.0(380.4 \pm 67.2)$ & 0.798 \\
\hline Sleep efficiency $(\%)$ & $89.1(87.9 \pm 8.3)$ & $90.0(86.8 \pm 9.7)$ & $87.7(83.3 \pm 13.9)$ & $86.7(84.9 \pm 10.2)$ & 0.419 \\
\hline Wake after sleep onset (min) & $39.6(47.4 \pm 33.5)$ & $37.1(50.6 \pm 40.6)$ & $45.8(62.3 \pm 50.9)$ & $\begin{array}{l}51.2 \\
\quad(59.0 \pm 42.1)\end{array}$ & 0.313 \\
\hline Stage $1(\%$ TST $)$ & $7.8(11.0 \pm 10.2)$ & $5.6(8.4 \pm 6.9)$ & $6.8(9.2 \pm 8.5)$ & $7.3(9.4 \pm 7.0)$ & 0.201 \\
\hline Stage $2(\%$ TST) & $70.9(73.3 \pm 13.0)$ & $78.3(76.2 \pm 12.2)$ & $74.3(73.2 \pm 11.1)$ & $\begin{array}{l}78.1 \\
\quad(77.0 \pm 11.2)\end{array}$ & 0.206 \\
\hline Stage 3/4 (\% TST) & $0.2(4.3 \pm 7.1)$ & $0.8(3.6 \pm 5.8)$ & $0.6(5.3 \pm 9.5)$ & $0.3(3.3 \pm 5.8)$ & 0.296 \\
\hline REM (\% TST) & $11.2(11.4 \pm 8.3)$ & $9.3(11.8 \pm 9.1)$ & $10.3(12.3 \pm 9.4)$ & $8.3(10.3 \pm 8.0)$ & 0.407 \\
\hline Sleep onset latency (min) & $4.0(9.0 \pm 12.1)$ & $4.6(8.8 \pm 10.5)$ & $4.3(12.9 \pm 28.4)$ & $4.0(9.0 \pm 13.6)$ & 0.575 \\
\hline
\end{tabular}

Data are expressed as median (mean \pm standard deviation)

${ }^{a}$ Pairwise comparisons, using the Wilcoxon signed-rank test and undergoing Bonferroni adjustment, indicated that the arousal index was significantly ( $p=0.021$ ) greater during ASV manual (PSmin 6) titration compared to CPAP. No significant differences were noted for CPAP versus ASV manual (PSmin 6) $(p=0.288)$ or ASV versus ASV manual (PSmin 6) $(p>0.99)$ 
Table 7 Comparison of respiratory disturbance indices between CPAP titration and at-home use

\begin{tabular}{|c|c|c|c|c|c|c|}
\hline & \multicolumn{6}{|l|}{ 3-month follow-up } \\
\hline & \multirow[t]{2}{*}{$\mathrm{AHI}(N=24)$} & \multirow[t]{2}{*}{$\mathrm{CAI}(N=24)$} & \multirow[t]{2}{*}{ OAI $(N=24)$} & \multirow[t]{2}{*}{$\mathrm{HI}(N=24)$} & \multicolumn{2}{|l|}{ Adherence } \\
\hline & & & & & All days & Days used \\
\hline CPAP titration & $11.3(20.3 \pm 21.8)$ & $2.6(10.3 \pm 13.5)$ & $3.0(5.2 \pm 6.7)$ & $3.5(5.3 \pm 5.5)$ & $2.4 \pm 2.3(N=5)$ & $3.7 \pm 1.6(N=5)$ \\
\hline ASV home use $\mathrm{a}^{\mathrm{a}}$ & $5.8(8.6 \pm 7.9)$ & $0.8(1.5 \pm 2.0)$ & $0.7(1.4 \pm 1.7)$ & $3.8(5.7 \pm 5.3)$ & $2.4 \pm 2.3(N=25)$ & $3.6 \pm 2.1(N=24)^{\mathrm{b}}$ \\
\hline$p$ value $^{\mathrm{c}}$ & 0.021 & 0.006 & 0.002 & 0.648 & & \\
\hline
\end{tabular}

Data are expressed as median (mean \pm standard deviation)

${ }^{a}$ The ASV auto and ASV manual (PSmin 6) data combined as the respiratory variables from patients using these devices were not significantly different (see Table 5)

${ }^{\mathrm{b}}$ One patient did not use the autoSV machine

${ }^{\mathrm{c}}$ Wilcoxon signed-rank test

booklet [35] providing information about CPAP can improve compliance and a similar booklet for this population would be strongly encouraged. However, our finding that respiratory indices were significantly improved with ASV treatment despite the low adherence rates attests to the unique efficacy of ASV treatment of SDB in chronic pain participants on high doses of opioids.

A significant limitation of this study is the high dropout rate. Of the 34 participants recruited, 31 completed the inlaboratory testing, but only 19 (44\% were either dropouts or were treated with CPAP) completed the 3-month at-home treatment phase. Intention-to-treat analyses were employed in this study to help reduce the impact of the dropouts on the study data. Further, although the only significant improvement in sleep architecture with treatment was a reduction in the arousal index; the arousal index was slightly higher with ASV manual PSmin 6 when compared with CPAP treatment. Slow-wave sleep levels were extremely low on the diagnostic night and did not improve with treatment. This alteration in sleep architecture is a likely consequence of the high milliequivalents taken by the study patients and the fact that opioid drugs suppress slow-wave sleep [36]. Others have also provided evidence that opioid use decreases slow-wave sleep in both healthy adults [37] and individuals with chronic pain [38].

It should be noted that the respiratory indices for the athome study phase were recorded using the automatic event detection algorithm in EncoreAnywhere. A previous report [39] documented a strong and significant correlation (intraclass correlation $=0.8, p<0.001$ ) for $\mathrm{AHI}$ and $\mathrm{AI}$ recorded by PSG when compared to automatic event detection of respiratory events using a positive airway pressure device. The device's algorithm did not differentiate obstructive from central events. The correlation for the HI was significant, but much lower (intra-class correlation $=0.3, p<0.001$ ).
The vicious cycle linking chronic pain and sleep disturbances is well established [40, 41]. Treatment of SDB in participants with chronic pain and on opioid therapy may reduce morbidity and mortality as a consequence of untreated SDB. A future publication from additional data collected during this study will document whether a treatment of SDB can lead to improvements in sleep, reduce pain levels, and improve daytime sleepiness, fatigue, and poor alertness.

Open Access This article is distributed under the terms of the Creative Commons Attribution License which permits any use, distribution, and reproduction in any medium, provided the original author(s) and the source are credited.

\section{References}

1. Institute of Medicine of the National Academies Report (2011) Relieving pain in America: a blueprint for transforming prevention, care, education, and research. http://www.iom.edu/Reports/2011/ Relieving-Pain-in-America-A-Blueprint-for-transformingPrevention-Care-Education-Research.aspx. Accessed 1 Aug 2014

2. A statement from the American Academy of Pain Medicine (2013) Use of opioids for the treatment of chronic pain. http://www. painmed.org/files/use-of-opioids-for-the-treatment-of-chronicpain.pdf. Accessed 1 Aug 2014

3. Volkow ND, McLellan TA, Cotto JH, Karithanom M, Weiss SR (2011) Characteristics of opioid prescriptions in 2009. JAMA 305(13):1299-1301

4. Young T, Peppard PE, Gottlieb DJ (2002) Epidemiology of obstructive sleep apnea: a population health perspective. Am J Respir Crit Care Med 165(9):1217-1239

5. Bahammam A, Delaive K, Ronald J, Manfreda J, Roos L, Kryger MH (1999) Health care utilization in males with obstructive sleep apnea syndrome two years after diagnosis and treatment. Sleep 22(6):740-747

6. He J, Kryger MH, Zorick FJ, Conway W, Roth T (1988) Mortality and apnea index in obstructive sleep apnea. Experience in 385 male patients. Chest 94(1):9-14 
7. Netzer NC, Stoohs RA, Netzer CM, Clark K, Strohl KP (1999) Using the Berlin questionnaire to identify patients at risk for the sleep apnea syndrome. Ann Intern Med 131(7):485-491

8. Nicholson B, Passik SD (2007) Management of chronic noncancer pain in the primary care setting. South Med J 100(10):1028-1036

9. Watson CP (2012) Opioids in chronic noncancer pain: more faces from the crowd. Pain Res Manag 17(4):263-275

10. Walker JM, Farney RJ, Rhondeau SM, Boyle KM, Valentine K, Cloward TV, Shilling KC (2007) Chronic opioid use is a risk factor for the development of central sleep apnea and ataxic breathing. J Clin Sleep Med 3(5):455-461

11. Jungquist CR, Flannery M, Perlis ML, Grace JT (2012) Relationship of chronic pain and opioid use with respiratory disturbance during sleep. Pain Manag Nurs 13(2):70-79

12. Teichtahl H, Wang D, Cunnington D, Quinnell T, Tran H, Kronborg I, Drummer OH (2005) Ventilatory responses to hypoxia and hypercapnia in stable methadone maintenance treatment patients. Chest 128(3):1339-1347

13. Hajiha M, DuBord MA, Liu H, Horner RL (2009) Opioid receptor mechanisms at the hypoglossal motor pool and effects on tongue muscle activity in vivo. J Physiol 587(11):2677-2692

14. Mezzanotte WS, Tangel DJ, White DP (1996) Influence of sleep onset on upper-airway muscle activity in apnea patients versus normal controls. Am J Respir Crit Care Med 153(6 Pt 1):1880-1887

15. Farney RJ, Walker JM, Cloward TV, Rhondeau S (2003) Sleepdisordered breathing associated with long-term opioid therapy. Chest 123(2):632-639

16. Gilmartin GS, Daly RW, Thomas RJ (2005) Recognition and management of complex sleep-disordered breathing. Curr Opin Pulm Med 11(6):485-493

17. Javaheri S, Smith J, Chung E (2009) The prevalence and natural history of complex sleep apnea. J Clin Sleep Med 5(3):205-211

18. Cassel W, Canisius S, Becker HF, Leistner S, Ploch T, Jerrentrup A, Vogelmeier C, Koehler U, Heitmann J (2011) A prospective polysomnographic study on the evolution of complex sleep apnoea. Eur Respir J 38(2):329-337

19. Javaheri S, Goetting MG, Khayat R, Wylie PE, Goodwin JL, Parthasarathy S (2011) The performance of two automatic servoventilation devices in the treatment of central sleep apnea. Sleep 34(12):1693-1698

20. Javaheri S, Malik A, Smith J, Chung E (2008) Adaptive pressure support servoventilation: a novel treatment for sleep apnea associated with use of opioids. J Clin Sleep Med 4(4):305-310

21. Farney RJ, Walker JM, Boyle KM, Cloward TV, Shilling KC (2008) Adaptive servoventilation (ASV) in patients with sleep disordered breathing associated with chronic opioid medications for non-malignant pain. J Clin Sleep Med 4(4):311-319

22. Teschler H, Dohring J, Wang YM, Berthon-Jones M (2001) Adaptive pressure support servo-ventilation: a novel treatment for Cheyne-Stokes respiration in heart failure. Am J Respir Crit Care Med 164(4):614-619

23. Oldenburg O, Lamp B, Faber L, Teschler H, Horstkotte D, Topfer V (2007) Sleep-disordered breathing in patients with symptomatic heart failure: a contemporary study of prevalence in and characteristics of 700 patients. Eur J Heart Fail 9(3):251-257

24. Yoshihisa A, Suzuki S, Yamaki T, Sugimoto K, Kunii H, Nakazato K, Suzuki H, Saitoh S, Takeishi Y (2013) Impact of adaptive servo-ventilation on cardiovascular function and prognosis in heart failure patients with preserved left ventricular ejection fraction and sleep-disordered breathing. Eur J Heart Fail 15(5):543-550

25. Allam JS, Olson EJ, Gay PC, Morgenthaler TI (2007) Efficacy of adaptive servoventilation in treatment of complex and central sleep apnea syndromes. Chest 132(6):1839-1846

26. Ramar K, Ramar P, Morgenthaler TI (2012) Adaptive servoventilation in patients with central or complex sleep apnea related to chronic opioid use and congestive heart failure. J Clin Sleep Med 8(5):569-576

27. Iber C, Ancoli-Israel S, Chesson AL, Quan SF (2007) The AASM manual for the scoring of sleep and associated events. Rules, terminology and technical specifications. The American Academy of Sleep Medicine, Westchester

28. Ohayon MM (2005) Relationship between chronic painful physical condition and insomnia. J Psychiatr Res 39(2):151-159

29. Young T, Evans L, Finn L, Palta M (1997) Estimation of the clinically diagnosed proportion of sleep apnea syndrome in middleaged men and women. Sleep 20(9):705-706

30. Teichtahl H, Prodromidis A, Miller B, Cherry G, Kronborg I (2001) Sleep-disordered breathing in stable methadone programme patients: a pilot study. Addiction 96(3):395-403

31. Philippe C, Stoica-Herman M, Drouot X, Raffestin B, Escourrou P, Hittinger L, Michel PL, Rouault S, d'Ortho MP (2006) Compliance with and effectiveness of adaptive servoventilation versus continuous positive airway pressure in the treatment of Cheyne-Stokes respiration in heart failure over a six month period. Heart 92(3): 337-342

32. Sin DD, Mayers I, Man GC, Pawluk L (2002) Long-term compliance rates to continuous positive airway pressure in obstructive sleep apnea: a population-based study. Chest 121(2):430-435

33. Vermeire E, Hearnshaw H, Van Royen P, Denekens J (2001) Patient adherence to treatment: three decades of research. A comprehensive review. J Clin Pharm Ther 26(5):331-342

34. Shapiro GK, Shapiro CM (2010) Factors that influence CPAP adherence: an overview. Sleep Breath 14(4):323-335

35. Shapiro GK, Zalai D, Trajanovic N, Mallea J (2011) Sleep apnea. CPAP and me. Joli Joco Publications Inc., Markham

36. Dimsdale JE, Norman D, DeJardin D, Wallace MS (2007) The effect of opioids on sleep architecture. J Clin Sleep Med 3(1):33-36

37. Shaw IR, Lavigne G, Mayer P, Choinière M (2005) Acute intravenous administration of morphine perturbs sleep architecture in healthy pain-free young adults: a preliminary study. Sleep $28(6)$ : 677-682

38. Peles E, Schreiber S, Adelson M (2009) Documented poor sleep among methadone-maintained patients is associated with chronic pain and benzodiazepine abuse, but not with methadone dose. Eur Neuropsychopharmacol 19(8):581-588

39. Berry RB, Kushida CA, Kryger MH, Soto-Calderon H, Staley B, Kuna ST (2012) Respiratory event detection by a positive airway pressure device. Sleep 35(3):361-367

40. Moldofsky H, Scarisbrick P (1976) Induction of neurasthenic musculoskeletal pain syndrome by selective sleep stage deprivation. Psychosom Med 38(1):35-44

41. Call-Schmidt TA, Richardson SJ (2003) Prevalence of sleep disturbance and its relationship to pain in adults with chronic pain. Pain Manag Nurs 4(3):124-133 